\title{
Disease Severity in Patients with Simultaneous Influenza and Bacterial Pneumonia
}

\author{
Masafumi Seki ${ }^{1,2,3}$, Kosuke Kosai ${ }^{1,2,3}$, Katsunori Yanagihara ${ }^{2}$, Yasuhito Higashiyama ${ }^{1}$, \\ Shintaro Kurihara ${ }^{2}$, Koichi Izumikawa ${ }^{1,2}$, Yoshitsugu Miyazaki ${ }^{1,2}$, Yoichi Hirakata ${ }^{1,2}$, \\ Takayoshi Tashiro $^{2}$ and Shigeru Kohno ${ }^{1}$
}

\begin{abstract}
Objective To determine the differences in the clinical features of bacterial pneumonia patients between patients co-infected with influenza virus or not co-infected.

Methods Fifteen adult patients with bacterial pneumonia ( 7 men and 8 women) who also tested positive for influenza virus antigen were compared with those with bacterial pneumonia alone $(n=28)$.

Results Complications with chronic lung diseases were more frequently found in bacterial pneumonia patients with influenza virus infection, compared with those who had bacteria pneumonia alone. Statistical differences were also found in body temperature, and heart rates between the two groups. CRP levels, chest Xray infiltrates and the severity of pneumonia, as determined using the criteria of the Japan Respiratory Society (JRS) and/or the Infectious Diseases Society of America (IDSA), were also significantly worse in patients of bacterial pneumonia infected with influenza virus, than in those who had bacterial pneumonia alone.

Conclusions The severity of pneumonia in patients co-infected with influenza virus and bacteria was significantly higher than in those infected with bacteria alone. These data suggested that the influenza virus infection enhanced the bacterial pneumonia. Further study of the pathogenesis of the synergic interaction between influenza virus and bacteria is warranted.
\end{abstract}

Key words: influenza virus, bacterial pneumonia, co-infection

(DOI: 10.2169/internalmedicine.46.6364)

\section{Introduction}

Influenza virus infection is a major respiratory infectious disease that generally induces bronchitis and pneumonia (1). The virus causes an acute febrile illness with malaise, and pneumonia can become lethal in the elderly when complications involve bacterial infections (2-5). Synergistic effects between influenza virus and bacteria have been suggested (6-9) and receptor-mediated pathways and other mechanisms are implicated in lethal synergism $(10,11)$.

We previously described fulminant pathological changes in the lungs of mice inoculated with Streptococcus pneumoniae ( $S$. pneumoniae) 2 days after influenza virus infection (12). The kinetics of viral titers, bacterial numbers and im- mune responses such as the release of cytokines and chemokines have shown that some critical immune mediators, such as Toll-like receptor (TLR) /mitogen-activated protein kinase (MAPK) signaling, cyclooxygenase (COX) expression and prostaglandin E2 (PGE2) production are increased (12).

Furthermore, chronic Pseudomonas aeruginosa (P. aeruginosa) infection in mice is exacerbated by the influenza virus, and decreased neutrophil function due to viral infection might be one inducer of lethal pneumococcal pneumonia in such mice (13-15). These results suggest that the synergistic effects of co-infection with influenza virus and bacteria are mediated through immune reactions. Here, we examined the clinical features of bacterial pneumonia affected by influenza virus co-infection.

\footnotetext{
${ }^{1}$ Department of Molecular Microbiology and Immunology, Nagasaki University Graduate School of Biomedical Sciences, Nagasaki, ${ }^{2}$ Second Department of Internal Medicine, Nagasaki University School of Medicine, Nagasaki and ${ }^{3}$ Kitakyushu City Yahata Hospital, Fukuoka Received for publication November 10, 2006; Accepted for publication February 6, 2007

Correspondence to Dr. Masafumi Seki, seki@nagasaki-u.ac.jp
} 
Table 1. Clinical Characteristics of 15 Patients with Bacterial Pneumonia Co-Infected with Influenza Virus

\begin{tabular}{|c|c|c|c|c|c|c|c|c|c|c|c|}
\hline Pt.\# & Age & Gender & Complications & Bacteria & $X p$ & Temp. & HR & RR & WBC & CRP & $\mathrm{PaO}_{2}$ \\
\hline 1 & 75 & M & Asthma & S.pneumoniae & $1 / 3<$ & 38.9 & 94 & 26 & 11950 & 2.5 & 70.2 \\
\hline 2 & 77 & F & Tumor, old Tbc & S. pneumoniae & $2 / 3>$ & 41.0 & 100 & 30 & 13600 & 25.4 & 58.5 \\
\hline 3 & 75 & M & Brain, tumor & S. pneumoniae & $1 / 3<$ & 37.5 & 100 & 20 & 6160 & 0.7 & 69.0 \\
\hline 4 & 68 & M & Old Tbc & S. pneumoniae & $2 / 3>$ & 37.7 & 95 & 24 & 22910 & 14.6 & 85.0 \\
\hline 5 & 58 & M & IPF & S. pneumoniae & $1 / 3<$ & 40.0 & 112 & 28 & 3670 & 8.5 & 60.5 \\
\hline 6 & 77 & F & Liver, old Tbc & S. pneumoniae & $2 / 3>$ & 37.4 & 90 & 48 & 13210 & 20.8 & 37.0 \\
\hline 7 & 81 & F & CHF, COPD & S. pneumoniae & $2 / 3>$ & 34.1 & 125 & 10 & 13700 & 32.7 & 85.3 \\
\hline 8 & 74 & M & Tumor,COPD. & S. pneumoniae & middle & 38.1 & 105 & 24 & 6920 & 6.9 & 69.5 \\
\hline 9 & 21 & F & None & S. pneumoniae & $1 / 3<$ & 39.1 & 96 & 14 & 12530 & 8.7 & 90.0 \\
\hline 10 & 84 & $\mathrm{~F}$ & CHF, COPD. & S. pneumoniae & $2 / 3>$ & 38.1 & 105 & 24 & 13000 & 15.0 & 94.0 \\
\hline 11 & 19 & M & None & H. influenzae & $1 / 3<$ & 39.0 & 62 & 20 & 8740 & 7.0 & 92.0 \\
\hline 12 & 19 & M & None & S. aureus & $1 / 3<$ & 38.6 & 90 & 20 & 5450 & 3.5 & 86.5 \\
\hline 13 & 88 & F & old Tbe & S. milleri & middle & 38.6 & 96 & 24 & 7870 & 14.2 & 78.5 \\
\hline 14 & 77 & $\mathrm{~F}$ & $\mathrm{CHF}$, asthma & S. aureus & $1 / 3<$ & 39.1 & 72 & 18 & 4610 & 5.3 & 89.3 \\
\hline 15 & 57 & $\mathrm{~F}$ & Asthma & M. catarrhalis & $1 / 3<$ & 37.5 & 66 & 18 & 7320 & 0.7 & 88.5 \\
\hline
\end{tabular}

COPD, chronic obstructive lung disease; Tbe, tubereulosis, IPF, idiopathic pulmonary fibrosis; CHF, chronic heart failure; tumor, malignant neoplasm; S. pneumoniae,

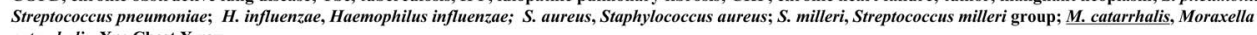
catarrhalis, $\mathrm{Xp}$; Chest $\mathrm{X}$ ray

\section{Materials and Methods}

\section{Patients and diagnostic criteria}

Fifteen consecutive patients who attended our hospital between December 2003 and April 2004 were diagnosed with concurrent influenza virus infection and bacterial pneumonia on admission. Influenza virus infection was confirmed using a rapid antigen detection kit (Espline Influenza A\&B-N; Fujirebio, Tokyo, Japan) by nasopharyngeal swab samples. In addition, they had fever, cough, and yellow sputum when they attended the hospital, and we found infiltrated shadows on chest X-rays. Specific bacteria, including S. pneumonaie, Haemophilus influenzae (H. influenzae), Streptococcus milleri (S. milleri), Staphylococcus aureus (S. aureus), and Moraxella catarrhalis (M. catarrhalis) were cultured from the sputum samples, and diagnosed as bacterial pneumonia co-infected with influenza virus.

Patients were diagnosed with bacterial pneumonia alone $(n=28)$ when nasopharyngeal swabs were negative for influenza virus antigen, but cough and sputum were accompanied by an infiltration shadow on chest X-rays.

Pneumonia was defined as the presence of symptoms of lower respiratory tract infection along with a new infiltrate on chest radiography and no emerging alternative diagnosis. The diagnosis of bacterial pneumonia was considered probable in patients with sputum culture positive for the bacteria. It was classified as definite if one of the following criteria was met: a culture yielding the bacteria exclusively, or the presence of the organism in: 1) blood culture; 2) pleural fluid; 3) a transthoracic needle aspirate; 4) a tracheobronchial aspirate with $\geq 10^{5} \mathrm{cfu} / \mathrm{ml}$; 5) a protected specimen brush (PSB) sample with $\geq 10^{3} \mathrm{cfu} / \mathrm{ml}$; 6) a bronchoalveolar lavage fluid (BALF) specimen with $\geq 10^{4} \mathrm{cfu} / \mathrm{ml}$; or 7) sputum with $\geq 10^{7} \mathrm{cfu} / \mathrm{ml}$ (16).

All patients and volunteers provided informed consent to participate in all procedures associated with the study, and the protocol of this study was approved by the ethics committee of Nagasaki University and Kitakyushu Yahata Hospital.

\section{Assessment of severity}

Pneumonia severity was assessed using the clinical severity scale published by the Japan Respiratory Society (JRS: Japan) $(17,18)$ and/or Infectious Diseases Society of America (IDSA: USA) on admission (2). In brief, pneumonia severity was classified by the JRS as mild, moderate or severe, depending on the results of a physical examination (body temperature, pulse rates, respiratory rates and dehydration) and laboratory data (WBC, CRP and $\mathrm{PaO}_{2}$ ). The Pneumonia Severity Index (PSI) of the IDSA was also calculated from data regarding age, complications, a physical examination and laboratory data on admission.

Chest X-ray findings were reviewed and assessed by three physicians blindly, and then the levels of infiltrates were determined.

\section{Data collection and statistical analysis}

Demographic data were normally distributed and analyzed with analysis of variances with Fisher's test for multiple comparisons. Clinical data of the patients were not normally distributed and were statistically analyzed with nonparametric statistics: Mann-Whitney U-rank test. Where necessary, the results were further corrected using the Bonferroni method. Spearman's rank correlation was used to examine the relationships between various parameters. All data are expressed as means \pm S.D and analyzed by using Stat View software (Abacus Concepts, Cary, NC, USA). A $p$-value below 0.05 denoted a statistically significant difference.

\section{Results}

\section{Patients}

Table 1 shows the demographics and baseline characteristics of the 15 patients with both bacterial pneumonia and influenza. Respiratory tract cultures were positive in all of the patients and S. pneumoniae was isolated from 10 of these patients. S. aureus was isolated from two patients, and $H$. influenzae, S. milleri and M. catarrhalis was isolated from one co-infected patient each. On the other hand, bacterial 
Table 2. Subject Demographics

\begin{tabular}{lcc}
\hline & Flu.(-) $(\mathrm{n}=28)$ & Flu. $(+)(\mathrm{n}=15)$ \\
\hline Age & $68.3 \pm 15.4$ & $69.1 \pm 18.3$ \\
Gender (Male/Female) & $17 / 11$ & $7 / 8$ \\
Complicatins & $25(89.3 \%)$ & $12(80.0 \%)$ \\
Chronic Lung Diseaes & $12 / 28(42.9 \%)$ & $11 / 15(73.3 \%) \$$ \\
Chronic Heart failure & $4 / 28(14.3 \%)$ & $3 / 15(20.0 \%)$ \\
Neoplastic Diseasess & $4 / 28(14.3 \%)$ & $3 / 15(20.0 \%)$ \\
Old Cerebral Infarction & $3 / 28(10.7 \%)$ & $1 / 15(6.7 \%)$ \\
Liver Diseaes & $2 / 28(7.1 \%)$ & $1 / 15(6.7 \%)$ \\
Collagen Diseaes & $1 / 28(3.6 \%)$ & $0 / 15(0.0 \%)$ \\
& & \\
\hline
\end{tabular}

Age are expressed as means \pm SD.

$\$ \mathbf{p}<0.05$ between groups, Fisher's PLSD test.

pneumonia alone patients consisted of pneumonia due to $S$. pneumoniae infection $(\mathrm{n}=21), H$. influenzae $(\mathrm{n}=5)$, and $M$. catarrhalis $(\mathrm{n}=2)$ (data not shown).

The male/female ratio did not differ substantially between the two groups, and the age of patients diagnosed with bacterial pneumonia alone (68.3 years) and co-infection (69.1 years) were also similar (Table 2).

Co-infected patients also had complications such as chronic lung disease $(n=11$ : old tuberculosis, 4; bronchial asthma, 3; COPD, 3; idiopathic pulmonary fibrosis, 1) chronic heart failure $(n=3)$, neoplastic diseases $(n=3)$, old cerebral infarction $(n=1)$ and liver disease $(n=1)$. Among complications, chronic lung diseases were significantly found in co-infected patients, compared with bacterial pneumonia alone patients.

\section{Physical examinations and laboratory data}

Fever was the most common frequent physical finding and the temperature was higher in co-infected patients, compared with those infected with bacteria alone (Table 3). Heart rates, but not respiratory rates were higher in the coinfected patients. Co-infected patients were not significantly dehydrated, in comparison to patients with bacterial pneumonia alone. The laboratory data revealed a significantly higher C-reactive protein (CRP; mean $11.1 \mathrm{mg} / \mathrm{dl}$; range 0.7 to $32.7 \mathrm{mg} / \mathrm{dl}$ ) in co-infected patients than in those with bacterial infection alone. However, white blood cell count (WBC) was not significantly different between co-infected patients and bacterial pneumonia alone patients, and $\mathrm{PaO}_{2}$ did not significantly differ between the 2 groups of patients.

Chest infiltrates comprised the most common radiographic abnormality in co-infected patients. Those with mild levels ( 8 of $15,53.4 \%$ ) had less than one-third of the lateral lung field occupied by infiltrates; those with severe levels had infiltrates occupying over two-thirds of the lateral lung field (severe level: $n=5,33.3 \%$ ) and those with moderate levels lay between $(n=2,13.3 \%)$. On the other hand, X-rays showed that all patients infected with bacteria alone had in- filtrates covering over one-third of the lateral lung: moderate $(n=6)$ and severe $(n=2)$ infiltrates accounted for $21.4 \%$ and $7.1 \%$, respectively, of those infected with bacteria alone (Table 3). Levels of chest X-rays findings were significantly more severe in co-infected patients than bacterial pneumonia alone.

\section{Severity of pneumonia}

The severity of bacterial pneumonia in the presence of influenza virus was assessed by the criteria of both the JRS and the PSI of IDSA. The co-infected patients were evaluated by the JRS criteria as having severe $(3 / 15,20.0 \%)$, moderate $(9 / 15,60.0 \%)$ and mild $(3 / 15,20.0 \%)$ pneumonia. Severe $(1 / 28,3.6 \%)$, moderate $(7 / 28,21.4 \%)$, and mild (20/ $28,71.4 \%$ ) pneumonia was found in patients with only bacterial infection alone (Table 3 ).

The PSI of IDSA criteria identified $86.1 \pm 29.5$ in coinfected patients, $67.3 \pm 21.3$ in bacteria infected alone patients (Table 3). The PSI of the co-infected patients was significantly higher than those of patients infected with bacteria pneumonia alone.

\section{Discussion}

The "Spanish flu" pandemic of 1918 was responsible for $>20$ million deaths worldwide $(19,20)$, a new strain of influenza (H5N1) caused many deaths in Hong Kong during 1997 and recently an avian type influenza (21) has become an epidemic. Pathological analyses of patients who succumbed to these infections have suggested that death was characteristically due to multi-system organ failure, including fulminant pneumonia: an acute respiratory distress syndrome-like process in the lung. However, the pathogenesis of the lung damage remains controversial. Our previous investigation and other studies have identified acute lung haemorrhage with massive pneumonia in the lungs of mice co-infected with influenza virus and bacteria, whereas infection with either influenza virus or $S$. pneumoniae alone in- 
Table 3. Clinical Data and Severity of Pneumonia

\begin{tabular}{|c|c|c|}
\hline & Flu.(-) $(n=28)$ & Flu. $(+)(n=15)$ \\
\hline $\begin{array}{l}\text { Body } \\
\text { Temperature }\left({ }^{\circ} \mathrm{C}\right)\end{array}$ & $37.2 \pm 0.9$ & $38.2 \pm 8.2 \div$ \\
\hline Heart Rates(/min.) & $87.3 \pm 17.9$ & $102.2 \pm 10.3 \%$ \\
\hline $\begin{array}{l}\text { Respiratory } \\
\text { Rates (min.) }\end{array}$ & $23.7 \pm 6.1$ & $24.8 \pm 10.2$ \\
\hline Dehydration & $23 / 28(82.1 \%)$ & $14 / 15(93.3 \%)$ \\
\hline $\mathbf{W B C}(/ \mathbf{m m} 3)$ & $11045.6 \pm 4603.7$ & $10109 \pm 5000.1$ \\
\hline CRP (mg/dl) & $5.9 \pm 6.5$ & $11.1 \pm 9.4 \ddagger$ \\
\hline $\mathrm{PaO}_{2}$ (Torr) & $70.5 \pm 3.1$ & $76.2 \pm 16.0$ \\
\hline \multicolumn{3}{|l|}{ Chest Infiltrates(\#): } \\
\hline $\begin{array}{l}>2 / 3 \\
\text { Middle } \\
<1 / 3\end{array}$ & $\begin{array}{c}2(7.1 \%) \\
6(21.4 \%) \dagger \\
20(71.4 \%) \dagger\end{array}$ & $\begin{array}{l}5(33.3 \%) \div \\
2(13.3 \%) \\
8(53.4 \%)\end{array}$ \\
\hline \multicolumn{3}{|c|}{ Pneumonia Severity (JRS, \#): } \\
\hline $\begin{array}{l}\text { Severe } \\
\text { Moderate } \\
\text { Mild }\end{array}$ & $\begin{array}{c}1(3.6 \%) \\
7(25.0 \%) \\
20(71.4 \%)+\end{array}$ & $\begin{array}{l}3(20.0 \%) \div \\
9(60.0 \%) \div \\
3(20.0 \%)\end{array}$ \\
\hline $\begin{array}{l}\text { Severity } \\
\text { Index } \\
\text { (IDSA) }\end{array}$ & $67.3 \pm 21.3$ & $86.1 \pm 29.5$ \\
\hline $\begin{array}{l}\text { JRS, } \\
\text { Data } \\
+\mathbf{p}<0 \\
\text { NS }=\end{array}$ & $\begin{array}{l}\text { Respiratory Society; } \\
\text { pressed as means } \pm \\
\text { ween groups } 2 \text { and } 3 \\
\text { ificant }\end{array}$ & $\begin{array}{l}\text { ctious Diseases Society of America. } \\
\text { hitney U rank test. }\end{array}$ \\
\hline
\end{tabular}

duces only moderate pneumonia $(6,12)$. Superinfected mice died significantly earlier than mice infected with one type of organism, due to severe fulminant lung damage rather than septic changes. These data suggest that extant influenza virus infection plays a key role in the pathogenesis of lethal lung diseases.

Here, we analyzed patients with bacterial pneumonia and influenza, and compared them with patients with bacterial pneumonia alone. The physical condition and laboratory data were significantly worse in co-infected patients compared with those infected with bacteria alone. X-ray infiltrates and the severity of pneumonia were also significantly increased in co-infected patients.

In demographics of patients, age and rates of complications were almost the same between co-infected and bacterial pneumonia alone patients, however, the rates of underlying chronic lung diseases were significantly higher in coinfected patients compared with those with bacterial pneumonia alone. Furthermore, three severe pneumonia cases were found in co-infected patients (patients \#2, 7, 10 in Table 1), and all these patients had chronic lung disease, including COPD and old tuberculosis. Three patients without underlying diseases showed mild or moderate pneumonia (patients \#9, 11, 12 in Table 1). These data suggested that underlying chronic lung diseases may be one of the most important factors that affect the pneumonia severity. It has been suggested that the incidence of secondary bacterial pneumonia is most common in elderly and in those with underlying diseases, and vaccinations against influenza virus and $S$. pneumoniae infection are recommended for those patients (1-5). Here, 8 of 15 co-infected patients and 14 of 28 bacterial pneumonia alone patients were vaccinated against influenza virus $(53.3 \%$ vs $50 \%$, not significant differences: data not shown), and none of the patients had been vaccinated for $S$. pneumoniae. An increase of vaccinated patients in Japan, especially against $S$. pneumoniae is necessary as soon as possible.

The present data suggest that a synergistic effect of viral and bacterial co-infection is related to the pathogenesis of severe pneumonia; that is, the influenza virus enhances the severity of bacterial pneumonia. The synergy between bacteria and virus were also found in other pathogens $(22,23)$. In influenza virus infection, severe pneumonia due to bacterial infection was reported in the pandemics of 1957-1958 (24) and 1995-1996 season (25). Influenza virus infection causes phagocytic cell dysfunction, damage to ciliated epithelium, tissue edema and other obscure disturbances of normal host defense mechanisms (26-29). These changes might be associated with increased adherence of bacteria and the prevalence of secondary bacterial diseases principally due to $S$. pneumoniae, $H$. influenzae and $S$. aureus. $(30,31)$.

Severe pneumonia develops after co-infection with bacte- 
ria and influenza virus, it rapidly progresses, and is mediated by host immune mechanisms. Impaired neutrophil function with decreased lysozyme secretion and bactericidal activity might foster bacterial colonization in the respiratory tract after influenza infection, and IL-6, IL-8 and RANTES are induced in human NCI-H292 bronchial epithelial cells by influenza virus infection $(13,29,32)$. We and Abramson et al analyzed co-infected mice and found an increase of immune molecules and a decrease in neutrophil function (1315). These studies suggested that host immune reactions contribute to the pathogenesis of severe bacterial pneumonia due to co-infection of influenza virus infection. We therefore measured the concentrations of cytokines, including IL-6, RANTES, and soluble ICAM-1 in the sera of the patients in this study, but unfortunately, there was no difference be- tween the two groups (data not shown). All patients in this study recovered, in contrast, all mice died in our previous mice study, in which IL-6 and RANTES were significantly increased in those mice lungs (12).

In conclusion, pneumonia was more severe in patients coinfected with influenza virus and bacteria, than in those with bacteria alone. Underlying chronic lung diseases may be the important factor in the frequent increase in secondary bacterial infection and subsequent development of severe pneumonia. Such severe pneumonia might be initiated by the influenza virus and mediated by the host immune response. Further studies are necessary to more precisely elucidate the pathogenesis of lung pathology and to identify effective treatment and prevention.

\section{References}

1. Murphy BR, Webster R. Fields Virology, Third Edition. Lippincott-Raven Publishers, Philadelphia, 1996.

2. Infectious Diseases Society of America. Practice Guidelines for the Management of Community-Acquired Pneumonia in Adults. Clinical Infectious Diseases 31: 347-382, 2000.

3. Glezen WP, Greenberg S, Atmar RL, Piedra PA, Couch RB. Impact of respiratory virus infections on persons with chronic underlying conditions. JAMA 283: 499-505, 2000.

4. Woodhead M, Blasi F, Ewig S, et al. Guidelines for the management of adult lower respiratory tract infections. Eur Respir J 26: 1138-1180, 2005.

5. American Thoracic Society. Guidelines for management of adults with community-acquired pneumonia. Am J Respir Crit Care Med 63: 1730-1754, 2001.

6. McCullers JA, Rehg J. Lethal synergism between influenza virus and Streptococcus pneumoniae: characterization of a mouse model and the role of platelet-activating factor receptor. J Infect Dis 186: 341-350, 2002.

7. McCullers JA. Effect of antiviral treatment on the outcome of secondary bacterial pneumonia after influenza. J Infect Dis 190: 519526, 2004.

8. McCullers JA, Bartmess K. Role of neuraminidase in lethal synergism between influenza virus and Streptococcus pneumoniae. J Infect Dis 187: 1000-1009, 2004.

9. Peltola VT, Murti K, McCullers JA. Influenza virus neuraminidase contributes to secondary bacterial pneumonia. J Infect Dis 192: 249-257, 2005.

10. van der Sluijs KF, van Elden L, Nijhuis M, et al. Involvement of the platelet-activating factor receptor in host defense against Streptococcus pneumoniae during postinfluenza pneumonia. Am J Physiol Lung Cell Mol Physiol 290: L194-L199, 2006.

11. van der Sluijs KF, van Elden L, Nijhuis M, et al. IL-10 is an important mediator of the enhanced susceptibility to pneumococcal pneumonia after influenza infection. J Immunol 172: 7603-7609, 2004.

12. Seki M, Yanagihara K, Higashiyama Y, et al. Immunokinetics in severe pneumonia due to influenza virus and bacteria coinfection in mice. Eur Respir J 24: 143-149, 2004.

13. Seki M, Higashiyama Y, Tomono K, et al. Acute infection with influenza virus enhances susceptibility to fatal pneumonia following Streptococcus pneumoniae infection in mice with chronic pulmonary colonization with Pseudomonas aeruginosa. Clin Exp Immunol 137: 35-40, 2004.

14. Abramson JS, Giebink G, Mills EL, Quie PG. Polymorphonuclear leukocyte dysfunction during influenza virus infection in chinchil- las. J Infect Dis 143: 836-845, 1981.

15. Abramson JS, Lyles D, Heller KA, Bass DA. Influenza A virusinduced polymorphonuclear leukocyte dysfunction. Infect Immun 37: 794-799, 1982.

16. Yanagihara K, Ohtsu Y, Ohno H, et al. Clinical characteristics of pneumonia caused by penicillin resistant and sensitive Streptococcus pneumoniae in Japan. Intern Med 43: 1029-1033, 2004.

17. Yanagihara K, Kohno S, Matsusima T. Japanese guidelines for the management of community-acquired pneumonia. Int J Antimicrob Agents 18: S45-S48, 2001.

18. Motomura K, Masaki H, Terada M, et al. Usefulness of the Japanese Respiratory Society guidelines for community pneumonia: a retrospective analysis of community-acquired pneumonia between 2000 and 2002 in a general hospital. Respirology 10: 208-214, 2005.

19. Taubenberger JK, Reid A, Krafft AE, Bijwaard KE, Fanning TG. Initial genetic characterization of the 1918 "Spanish" influenza virus. Science 275: 1793-1796, 1997.

20. Reid AH, Fanning T, Hultin JV, Taubenberger JK. Origin and evolution of the 1918 "Spanish" influenza virus hemagglutinin gene. Proc Natl Acad Sci USA 96: 1651-1656, 1999.

21. Chan MC, Cheuning C, Chui WH, et al. Proinflammatory cytokine responses induced by influenza A (H5N1) viruses in primary human alveolar and bronchial epithelial cells. Respir Res 6: 135-148, 2005.

22. Marien M, Decostere A, Martel A, Chiers K, Froyman R, Nauwynck H. Synergy between avian pneumovirus and Ornithobacterium rhinotracheale in turkeys. Avian Pathol 2005 34: 204-211, 2005.

23. Gershwin LJ, Berghaus L, Arnold K, Anderson ML, Corbeil LB. Immune mechanisms of pathogenetic synergy in concurrent bovine pulmonary infection with Haemophilus somnus and bovine respiratory syncytial virus. Vet Immunol Immunopathol 15: 119130, 2005.

24. Louria DB, Blumenfeld H, Ellis JT, Kilbourne ED, Rogers DE. Studies on influenza in the pandemic of 1957-1958. II. Pulmonary complications of influenza. J Clin Invest 21: 213-265, 1959.

25. O'Brien KL, Walters M, Sellman J, et al. Severe pneumococcal pneumonia in previously healthy children: the role of preceding influenza infection. Clin Infect Dis 30: 784-789, 2000.

26. Hussell T, Pennycook A, Openshaw PJ. Inhibition of tumor necrosis factor reduces the severity of virus-specific lung immunopathology. Eur J Immunol 31: 2566-2573, 2001.

27. Scheiblauer H, Reinacher M, Tashiro M, Rott R. Interactions between bacteria and influenza A virus in the development of influ- 
enza pneumonia. J Infect Dis 166: 783-791, 1992.

28. Sato K, Suga M, Akaike T, et al. Therapeutic effect of erythromycin on influenza virus-induced lung injury in mice. Am J Respir Crit Care Med 157: 853-857, 1998.

29. Pang G, Clancy R, Cong M, Ortega M, Zhigang R, Reeves G. Influenza virus inhibits lysozyme secretion by sputum neutrophils in subjects with chronic bronchial sepsis. Am J Resp Crit Care Med 161: 718-722, 2000.

30. Beckham JD, Cadena A, Lin J, et al. Respiratory viral infections in patients with chronic, obstructive pulmonary disease. J Infect 50: 1098-1196, 2005.

31. Oliveira EC, Marik P, Colice G. Influenza pneumonia: a descriptive study. Chest 119: 1717-1723, 2001.

32. Matsukura S, Kokubo F, Noda H, Tokunaga H, Adachi M. Expression of IL-6, IL-8, and RANTES on human bronchial epithelial cells, NCI-H292, induced by influenza virus A. J Allergy Clin Immunol 98: 1080-1087, 1996.

(C) 2007 The Japanese Society of Internal Medicine http://www.naika.or.jp/imindex.html 